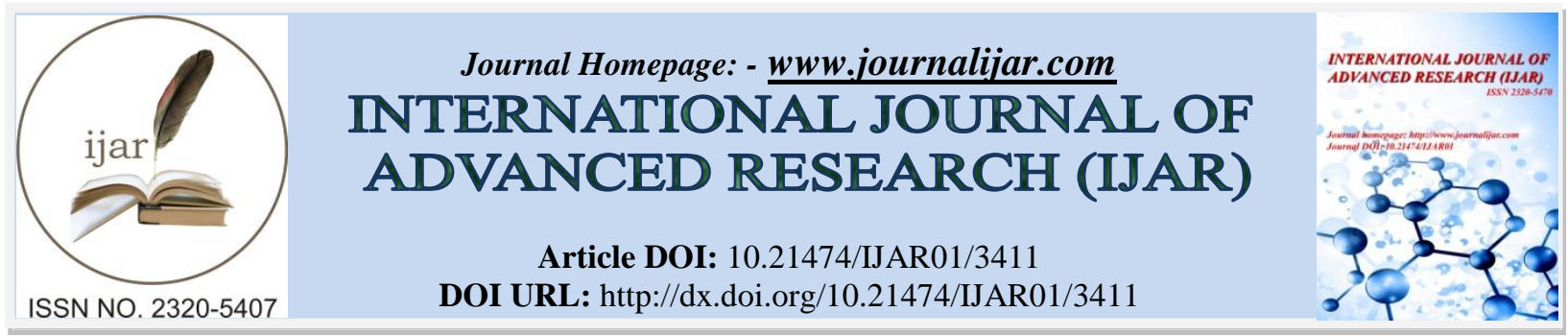

RESEARCH ARTICLE

\title{
KNOWLEDGE ON PRECONCEPTION CARE: AN ISSUE AMONG REPRODUCTIVE AGE WOMEN ATTENDING GYNAE/OBSTETRIC OPD OF NATIONAL MEDICAL COLLEGE.
}

Thakuri S. Rosy ${ }^{1}$ and ${ }^{*}$ Singh Babita ${ }^{2}$.

1. B. Sc Nursing Student, National Medical College Nursing Campus, Birgunj, Nepal.

2. Vice Principal, Associate Professor, National Medical College Nursing Campus, Birgunj, Nepal.

\section{Manuscript Info}

Manuscript History

Received: 10 December 2016

Final Accepted: 15 January 2017

Published: February 2017

Key words:-

knowledge, Preconception care,

Reproductive age women.

\section{Abstract}

Introduction: Preconception care is recognized as a critical component for both maternal and child health promotion. Preconception care may help to reduce the mortality and morbidity rates. Preconception is the integral part of antenatal care because it helps to reduce potential risk, promote healthy pregnancy and fetal outcome and improve readiness for pregnancy. It is designed for maintenance of health before pregnancy and to those who had previous problem with pregnancy.

Methods: The descriptive cross sectional study was carried out among 55 reproductive age women visiting the Gynecological/Obstetric OPD of National Medical College Teaching Hospital, Birgunj with the objective to find the knowledge on preconception care by using pretested structured interview schedule. The collected Data were analyzed by using SPSS and MS Excel.

Results: The study concludes that the majority $69.09 \%$ of reproductive age women had moderate knowledge regarding preconception care. There was significant association of knowledge regarding preconception care with occupation ( $\mathrm{P}$ value 0.025$)$ and area of residence ( $\mathrm{P}$ value 0.021 ) of the reproductive age women, whereas there was no association seen with the age, education, types of family, religion, no. of children and family monthly income.

Conclusions: The finding suggests that education and information booklet and various mass media should be developed to increase the level of knowledge on preconception care among reproductive age women.

Copy Right, IJAR, 2017,. All rights reserved.

\section{Introduction:-}

Pregnancy is a unique, exciting and often joyous time in a woman's life, as it highlights the woman's amazing creative and nurturing powers while providing a bridge to the future. (Evert, 2005)

Preconception care is the set of preventive, promotive and curative interventions given to the women before pregnancy with an intention of healthy mother and baby. Preconception care is designed for preventive measures, health maintenance and health promotion before pregnancy.

Corresponding Author:- Singh B.

Address:- Associate professor National Medical College Nursing Campus, Birgunj, Nepal. 
The aim of preconception care is to prepare your body for pregnancy, birth and beyond. This preparation ideally should occur at least four months prior to trying to fall pregnant. (Naish and Roberts, 1998)

There is evidence that health problems (like nutritional problems such as anemia and obesity, vaccine preventable diseases such as rubella) and problem behavior (like tobacco and alcohol, risk factors i.e. genetic conditions) can contribute to poor maternal and child health outcomes.

World Health Organization reports that more than half of all maternal deaths occur in Sub-Saharan Africa and nearly a third occur in South Asia ( Dovey, 2015) .Everyday in 2015, about 830 women died due to complications of pregnancy and childbirth.

By seeking the health care facilities and utilizing the family planning method, unplanned pregnancies can be prevented. Later gestational complications like pre eclampsia, macrosomia etc, it is found that preconception care is associated with improved outcome.

The objectives of the study were to assess the level of knowledge on preconception care and to find out the association between knowledge on preconception care with the selected demographic variables of reproductive age women.

\section{Materials \& Methods:-}

The descriptive cross sectional study was carried out among 55 reproductive aged women visiting Gynaecological/Obstetric OPD of National Medical College Teaching Hospital, Birgunj, Nepal. The sample size was determined on the basis of correct proportion of knowledge on preconception care which was found to be $15.42 \%$ as per the study conducted by Gautam and Dhakal (2015). Non probability sampling technique was adopted to select the women for data collection. The total 55 women of reproductive age were interviewed from 2073/5/232073/6/7 by using pretested structured interview schedule (Bhojpuri Version) which was developed in consultation with nine experts in respective fields. Knowledge score were categorized as adequate level (>75\% of the total score), moderate level $(50-75 \%$ of the total score) and inadequate level ( $<50 \%$ of the total score). The data were compiled and analyzed by using SPSS and MS Excel.

\section{Results:-}

The findings revealed that more than one third $36.36 \%$ of reproductive age women were of $20-24 \mathrm{yrs}$ of age, maximum $45.45 \%$ of them were illiterate, majority $74.54 \%$ of them were housewife, majority $67.27 \%$ of them belonged to joint family, more than half $60 \%$ belonged to Hindu religion, $30.90 \%$ of women had two children in number, majority $69.09 \%$ of them had monthly family income(in NRS) $5,000-25,000$, more than half $50.9 \%$ of women reside in urban area and more than one third $36.36 \%$ of women got information from radio/television.

Data shown in table 1 shows that majority of women were having moderate level of knowledge regarding preconception care. Data shown in table 2 shows the significant association of knowledge regarding preconception care with the occupation $(\mathrm{p}=0.025)$ and area of residence $(\mathrm{p}=0.021)$ of the reproductive age women

Table 1:- Frequency and Percentage of Knowledge Level of Reproductive Age Women Regarding Preconception

$$
\text { Care. }
$$

$\mathrm{n}=\mathbf{5 5}$

\begin{tabular}{|l|l|l|}
\hline Knowledge level & Frequency & Percentage \\
\hline Adequate knowledge & 6 & 10.91 \\
\hline Moderate knowledge & 38 & 69.09 \\
\hline Inadequate knowledge & 11 & 20 \\
\hline
\end{tabular}


Table 2:- Association of Knowledge Regarding Preconception Care with Selected Socio-Demographic Variable $\mathbf{n}=\mathbf{5 5}$

\begin{tabular}{|l|l|l|l|}
\hline Demographic Variables & $\begin{array}{l}\chi 2 \\
\text { value }\end{array}$ & Degree of freedom & $\begin{array}{l}\text { Asymptomatic Significant } \\
\text { (two sided) }\end{array}$ \\
\hline Age & 36.248 & 36 & 0.457 \\
\hline Education & 56.423 & 48 & 0.189 \\
\hline Occupation & 54.393 & 36 & $0.025^{*}$ \\
\hline Type of family & 15.886 & 12 & 0.197 \\
\hline Religion & 20.750 & 36 & 0.980 \\
\hline No of children & 40.466 & 36 & 0.280 \\
\hline $\begin{array}{l}\text { Family monthly income } \\
\text { (in NRS) }\end{array}$ & 43.583 & 36 & 0.180 \\
\hline Residence & 23.942 & 12 & $0.021^{*}$ \\
\hline
\end{tabular}

\section{Discussions:-}

The findings of this study revealed that more than one third $36.36 \%$ of reproductive age women were of $20-24 \mathrm{yrs}$ of age, maximum $45.45 \%$ of them were illiterate, majority $74.54 \%$ of them were housewife, majority $67.27 \%$ of them belonged to joint family, more than half $60 \%$ belonged to Hindu religion, $30.90 \%$ of women had two children in number, majority $69.09 \%$ of them had monthly family income(in NRS) 5,000-25,000, more than half 50.9\% of women reside in urban area and more than one third $36.36 \%$ of women got information from radio/television.

The findings of the study showed that more than two third $69.09 \%$ of reproductive age women were having moderate knowledge level regarding preconception care. Present study findings are in congruent with the similar study conducted by Gautam and Dhakal (2015) in Tulsipur municipality of Dang district, Nepal, among 227 reproductive age women to assess the knowledge on preconception care among reproductive age women. The study showed that reproductive age women have average level of knowledge regarding preconception care.

There was significant association of knowledge regarding preconception care with occupation and place of residence among reproductive age women. The result of the study was supported by quantitative study conducted at Saradha College of education, Salem and Gover Arts College for women to assess the level of knowledge regarding preconception care. The total sample was 100 . The sample was collected by non- probability convenient sampling technique. The study showed that there was significant association of knowledge regarding preconception care with the area of residence.

\section{Conclusion:-}

A descriptive cross-sectional study was conducted to assess the knowledge on preconception care among reproductive age women. In this study, total number of 55 reproductive age women was selected to assess the knowledge on preconception care. Majority $69.09 \%$ of the reproductive age women had moderate knowledge. The results showed that the knowledge level regarding preconception care was independent with age, education level, religion, type of family, no. of children, monthly income whereas was dependent on occupation and residence.

The findings of the study suggest more education and information should be needed to increase the level of knowledge regarding preconception care. Education to the women and couples about preconception care and promoting contraceptive use reduces the rapid and unplanned pregnancies. Education can be given in the health care setting, community as well as through different mass Medias.

\section{Acknowledgement:-}

I would like to express my deep gratitude to all the women of reproductive age who gave their consent to participate in study. I would also like to extend thanks to my research guide as well as the Hospital Director of National Medical College Teaching Hospital 


\section{References:-}

1. Evert, J. (2005). Introduction to pregnancy. Retrieved from http://www.mentalhelpnet/puc/view-doc.php?type

2. Gautam, P., \& Dhakal, R. (2016). Knowledge On Preconception Care Among Reproductive Age Women. Saudi Journal Medical \& Pharmaceutical Sciences. 2(1). Page no 1-6

3. Essays, UK. ( 2013). The Level Of Awareness Regarding Preconception Care Nursing Essay. Retrieved from https://www.ukessays.com/essays/nursing/the-level-of-awareness-regarding-preconception-care-nursingessay.php?cref $=1$

4. Naish, F., \& Roberts, J. (1998). The Natural Ways To better Babies. Australia

5. Dovey (2015). Maternal Mortality in 2015: We Succeded And Still Have Room For Improvement In Protecting Mother's Live.

6. Dean, S.V., Lassi, Z.A., Imam, A.M., \& Bhutta, Z.A. (2014). Preconception-Substance Abuse Prevention And Lifestyle Changes. Reproductive Health. 11(suppl 3)

7. Dean, S.V., Lassi, Z.A., Imam, A.M. \& Bhutta, Z.A. (2014). Preconception Care: Nutritional Status And Nutritional Interventions. Reproductive Health. 3(suppl 3):S3

8. Lassi, Z.A., Imam, A.M., Dean, S.V., \& Bhutta, Z.A. (2014). Preconception - Preventing And Treating Infection. Reproductive Health. 11 (suppl 3)

9. Lassi, Z.A., Imam, A.M., Dean, S.V., \& Bhutta, Z.A. (2014). Preconception - Screening And Management Of Chronic Disease Promoting Psychological Health. Reproductive Health. 11(suppl 3). 